\section{Providing healthcare through "value shops": impact on professional fulfilment for physicians and nurses}

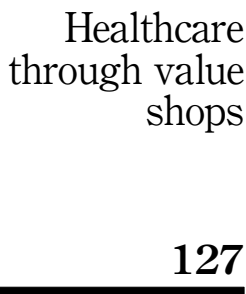

Christian Gadolin

University West, Trollhättan, Sweden and

Chalmers University of Technology, Gothenburg, Sweden

Thomas Andersson

University of Skövde, Skövde, Sweden and

Chalmers University of Technology, Gothenburg, Sweden, and

Erik Eriksson and Andreas Hellström

Chalmers University of Technology, Gothenburg, Sweden
Received 20 December 2019 Revised 3 March 2020 Accepted 5 March 2020

\begin{abstract}
Purpose - The purpose of this paper is to empirically explore and demonstrate the ability of healthcare professionals to attain professional fulfilment when providing healthcare inspired by "value shops".

Design/methodology/approach - A qualitative case study incorporating interviews and observations was conducted.

Findings - The empirical data suggest that the professional fulfilment of both physicians and nurses is facilitated when care is organized through "value shops". Both groups of professionals state that they are able to return to their "professional core".

Originality/value - The beneficial outcomes of organizing healthcare inspired by the "value shop" have previously been explored in terms of efficiency and quality. However, the professional fulfilment of healthcare professionals when providing such care has not been explicitly addressed. Professional fulfilment is vital in order to safeguard high-quality care, as well as healthcare professionals' involvement and engagement in implementing quality improvements. This paper highlights the fact that care provision inspired by the "value shop" may facilitate professional fulfilment, which further strengthens the potential positive outcomes of the "value shop" when utilized in a healthcare setting.
\end{abstract}

Keywords Value configuration, Value shop, Resource integration, Healthcare

Paper type Research paper

\section{Introduction}

Quality improvement (QI) has become widespread in healthcare systems worldwide (Chassin and Galvin, 1998; Bevan, 2010; Chassin et al., 2010), with healthcare professionals' involvement and engagement in QI constituting a cornerstone in ensuring its success (Gadolin and Andersson, 2017). Most contemporary QI utilizes pre-defined processes, patient pathways and patient flows (Eriksson, 2016; Gadolin, 2017) with the aim of mitigating the fragmentation of healthcare provision caused by "siloization" (Pollitt, 2003; Chrisensen and

(C) Christian Gadolin, Thomas Andersson, Erik Eriksson and Andreas Hellström. Published in International Journal of Health Governance. Published by Emerald Publishing Limited. This article is published under the Creative Commons Attribution (CC BY 4.0) licence. Anyone may reproduce, distribute, translate and create derivative works of this article (for both commercial \& non-commercial purposes), subject to full attribution to the original publication and authors. The full terms of this licence may be seen at: http://creativecommons.org/licences/by/4.0/legalcode

This work was supported by the The Swedish Research Council for Health, Working Life and Welfare (Forte) [2016-01124].

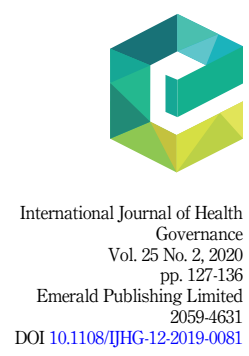


IJHG

25,2

Lægreid, 2011) and an intra-organizational focus (Cebul et al., 2008; Osborne et al., 2015; OtteTrojel et al., 2015; Kern et al., 2019). Whereas this linearity has proved efficient for certain types of healthcare services - where diagnosis and best practice are known - its shortcomings become particularly apparent when the patient suffers from symptoms that are not easily attributed to a specific condition or disease (Christensen et al., 2009). Since these patients are unable to "fit" pre-defined patient pathways or pre-defined disease treatment programmes (Eriksson, 2016) as no pre-defined route is able to provide their care in an integrated manner (e.g. Ouwens et al., 2005; Carroll et al., 2010; Nolte et al., 2012; Frandsen et al., 2015; Chen et al., 2016), they often see multiple distinct care providers that have little to no contact.

It seems that the "value chain" configuration model (Porter, 1985; Stabell and Fjeldstad, 1998), which conceptualizes value as being added in a pre-defined process of refinement, is unable to address the needs of patients with unknown conditions. Instead, the value shop (Stabell and Fjeldstad, 1998; Christensen et al., 2009) is a value configuration model - or a conceptual construct for creating value - that seems more fitting in putting the patient's perspective in focus, and hence enabling value creation through new ways of resource integration. The essential idea of value creation through the "value shop" stipulates that "value is created by mobilizing resources and activities to resolve a particular customer problem" (Stabell and Fjeldstad, 1998, p. 414). As such, it is distinct from the "value chain" value configuration model with its predisposition to conceptualize value as being added in a pre-defined process of refinement. Although it appears there has been a lack of efforts to innovate and integrate this organizing principle in healthcare (cf. Hwang and Christensen, 2008), multiple studies have highlighted the potential of care provided through means and methods similar to those of the "value shop" to achieve the desired qualities and outcomes, such as decreased costs, patients' experience of better care and timely diagnosis and treatment (Gui et al., 1995; Tang and Lee, 2009; Moore et al., 2009; Bredenhoff et al., 2010; Cook et al., 2014; King, 2016; Friedemann Smith et al., 2019; van Leersum et al., 2019). However, there are a lack of studies focussing on healthcare professionals' involvement and engagement in QI inspired by the "value shop". An important aspect of understanding the feasibility of successful QI inspired by the "value shop" in healthcare is thus missing.

The involvement of healthcare professionals is pivotal in all interventions aiming to achieve QIs in healthcare (Batalden and Davidoff, 2007), as those who are deemed not to be aligned with professional values often have difficulties in implementing change in practice (Audet et al., 2005; Reay and Hinings, 2009; Van den Broek et al., 2014; Gadolin and Andersson, 2017). Understanding how care provision through means and methods similar to those of the "value shop" may affect the ability of professional employees to attain professional fulfilment is thus pivotal in ensuring that such interventions can be anchored in practice. Interventions that are not able to cater for professional fulfilment have difficulties in achieving healthcare professionals' engagement and involvement (Lindgren et al., 2013). In addition, professional fulfilment is linked to the health of healthcare professionals, as well as to outcomes related to high-quality care (Trockel et al., 2018). It is thus vital to understand how providing care associated with the "value shop" affects the capacity to attain professional fulfilment, both to ensure the involvement and engagement of professional employees as well as their health and high-quality care. Studying the professional fulfilment of professional employees when providing care associated with the "value shop" is thus called for. In order to address this, the aim of this paper is to empirically explore and demonstrate the ability of healthcare professionals to attain professional fulfilment when engaged in providing healthcare inspired by "value shop".

\section{What is professional fulfilment for healthcare professionals?}

Professional fulfilment may be understood as an expanded version of job satisfaction (Thomsen et al., 1999). The conflict between professional and bureaucratic principles of organizing has long 
been identified as a major impediment to professional healthcare employees attaining professional fulfilment (Corwin, 1961). Although the potential to attain professional fulfilment is affected by multiple factors, the capacity of healthcare professionals, especially physicians, to exercise autonomy and professional freedom without restrictions and interference imposed by management is often pivotal (Barritt, 2005). Being able to work with what is perceived as the "core" of one's profession is thus pivotal in achieving professional fulfilment. However, the "core" of professional work for physicians and nurses is different. In highlighting these differences, Glouberman and Mintzberg (2001) argue that the "worlds" of physicians and nurses are divergent, which means that the core professional work performed by physicians and nurses is different. Whereas the professional work of physicians is inclined more towards swift interventions with the aim of treating and/or curing the patient, the professional work of nurses is predisposed towards attending to the patients' well-being and comfort for a longer period. These discrepancies are supported by empirical studies that have shown that nurses attain professional fulfilment when they are able to develop strong interpersonal relationships which facilitate high-quality care for patients (Utrianien, 2009), whereas physicians tend to achieve professional fulfilment when they are able to focus on successfully exercising their medical expertise (Bååthe and Norbäck, 2013). The capacity to achieve professional fulfilment is thus aligned with the ability to exercise professional judgement and discretion when performing professional work (Freidson, 1986, 2001). Hence, although physicians and nurses are dissimilar in terms of both the preconditions to exercise autonomy and what is perceived as being one's area of expertise (Gadolin, 2018), the ability to act in accordance with what is perceived as "core" to one's profession is identified as an important component in attaining professional fulfilment. Research concerning preconditions for physicians and nurses to attain professional fulfilment accords with contemporary literature on the necessity of aligning QIs in healthcare with the professional logics of healthcare professionals. In other words, in order for healthcare professionals to perceive QIs as meaningful and relevant, there must be a perception that their unique professional competence is utilized properly and that they are able to act with discretion (Gadolin and Andersson, 2017). Consequently, both the literature in relation to professional fulfilment and the research on institutional logics in healthcare settings (e.g. Reay et al., 2017: Anderson and Liff, 2018; Ernst, 2019) underscore the fact that healthcare professionals' ability to act in accordance with what they perceive as being "core" to their profession is vital in attaining professional fulfilment.

\section{Method and setting}

In order to fulfil the explorative aim of this paper, a qualitative research strategy was chosen as it enables such exploration while also facilitating the collection of in-depth data in relation to the phenomenon studied. As the study is of care provided by means and methods similar to those proposed by "value shops", the case study design was utilized as it further supports the researchers' ability to gather rich and nuanced data, and thus facilitates the in-depth analyses required to come close to a description of empirical reality. The case studied consisted of a Swedish pilot project - Diagnostic Centre (DC) - in which a dozen hospitals had moved away from a linear mode of working with patients with a wide range of symptoms potentially caused by cancer, to gathering staff members and resources around this patient category. The regional body facilitating knowledge development and governing medical interventions in relation to cancer diagnosis and treatment consented to the DC being the subject of this study. In order to minimize consideration of local discrepancies in the data collection, the case study consisted of in-depth data collection in relation to two hospitals. This approach aligns with what is described as a multiple case study (Miles and Huberman, 1994) so that valuecreating patterns, capacities and functions attributed to the organizing principle inherent in the $\mathrm{DC}$ become discernible and prominent in the data collected, rather than the potential

\section{Healthcare} through value shops

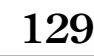


IJHG

25,2

influence of local idiosyncrasies. Representatives at both hospitals involved in the overarching development of the $\mathrm{DC}$ gave their consent to their respective organisations being studied in-depth and informed the healthcare professionals at each organisation that the study would take place. Both hospitals studied are located in southern Sweden and are medium-sized.

Data were collected through documents, observations and interviews. The policy documents were read and sorted in order to obtain a sense of the desired effects of the DC as well as how it was intended to implement the care at the DC. Studying the documents prior to performing the observations and interviews enabled them to be more informed, as a preliminary understanding of the desired effects and procedures at the DC had already been obtained. A total of seven observations were carried out. Five of these observations took place at workshops attended by representatives of the regional governing body, as well as by staff members from all the hospitals participating in the DC in order to share knowledge with each other. One observation took place at each hospital (i.e. two observations in total) where the DC was studied in greater detail. These local meetings were mainly centred on issues related to daily operations at the $\mathrm{DC}$. The observations ensured that the interviews were meaningful as it allowed the interviewer to expand on topics and interactions noted on these occasions and found to be of relevance for the physicians' and nurses' capacity to attain professional fulfilment. A total of 11 interviews were conducted with six physicians, three nurses and two medical secretaries. Each interviewee was directly involved in daily operations at the DC. The focus of the interviews was on exploring the physicians' and nurses' experience of working at the DC, as well as the conditions affecting their experiences. All interviewees confirmed they had given their informed consent to participate in the study before the interview was initiated. All interviews were transcribed verbatim in order to facilitate data analysis.

Qualitative data is not only analysed when all of the empirical data has been collected; instead it is a constantly on-going iterative process. Primary interpretations (Alvesson and Sköldberg. 2009) were made throughout the data collection process, which allowed subsequent observations and interviews to expand on relevant themes and topics that were found to be of interest, and enabled data collection to become more fruitful in relation to the purpose of the study. Secondary-level interpretations (ibid) were performed when all data had been collected and consisted of a qualitative conventional content analysis (Hsieh and Shannon, 2005). Qualitative data analysis software (NVivo) was used to ensure a methodical, thorough and attentive analysis process. The analysis began with multiple readings of observation notes and interview transcriptions, with data simultaneously sorted on the basis of similarities in regard to the experiences the physicians and nurses attained through utilizing means and methods suggested by the "value shop" value configuration at the DC. Patterns and connections identified in the sorted data were subsequently defined and sorted while iteratively discussed amongst the authors. It became apparent after this process that the benefits of applying the "value shop" configuration were associated with professional fulfilment for physicians as well as nurses. These two professions accounted for the majority of patient contact at the $\mathrm{DC}$ and will consequently be the focus of this paper. To achieve presentability, a vital step when conducting qualitative content analysis, the sorted data were reduced in order to present condensed, tangible and comprehensible findings in relation to the nurses' and physicians' attainment of professional fulfilment at the DC. Furthermore, these findings highlight plausible consequences of the "value shop" value configuration in healthcare provision in relation to how it might facilitate professional fulfilment. This way of analysing qualitative data aligns with what is proposed by Miles and Huberman's (1994) three steps: reducing data, displaying data and drawing conclusions. The quotes illustrated in the findings section are intended to be representative of the interpretations agreed upon throughout the data analysis process (Silverman, 2001). 


\section{Findings}

Professional fulfilment for physicians

The methods employed by physicians in working with their patients at the DC were very different from their ordinary way of working with patients. Instead of seeing a patient for a short time, often with long periods between a patient's visits, they were able to work intensely and actively with a patient over a period. This mode of working was deemed necessary to fulfil the aim of diagnosing patients with severe symptoms/suspected cancer within 18 days. This way of working with patients thus differed substantially from the ordinary way of working with suspected cancer patients, which entailed an initial search for more common diseases or conditions that may cause the symptoms exhibited, with the patient often seeing multiple care providers.

As a consequence of the short diagnosis period, the physician was not strictly limited in regard to the medical tests they might deem necessary to advance the medical investigation. This priority access to medical tests is contrary to normal care procedures, where it is only medical tests for the most likely diseases and conditions causing the severe symptoms that can be ordered. As the $\mathrm{DC}$ only has a few patients registered at the same time, the physician is able to quickly follow-up the medical test results in order to further advance the medical investigation. Furthermore, although multiple physicians were engaged at the DC, often just one physician was actively involved in the diagnoses of patients currently enrolled.

In addition, the physicians at the $\mathrm{DC}$ had established connections with other departments and clinics within the hospital. These connections allow the patients at the DC to be given priority when scheduled patients cancelled their appointments - facilitating the intense diagnosis procedure. Moreover, networks with other hospitals and medical specialists have enabled similar arrangements to be established with other care providers; further enabling the patients at the DC to obtain the specialized care and guidance necessary - even when it is unavailable at the local hospital.

All physicians stated that that this way of working with patients enabled them to get back to their "professional core". In many cases, they said that working at the DC changed their professional role into what it "ought to be". This core was constituted by the medical expertise specific to a physician, arising from their more extensive medical studies, but also by the notion that it was possible to exercise this medical expertise freely and with discretion for the successful diagnosis of the patient. One physician, who had substantial experience from primary care centres, articulated the characteristic feature of working as a physician at the DC:

Most of the things I do at the primary care centre could be done by some other profession [(e.g., a nurse]), but the things I do at the Diagnostic Centre truly require a physician. When working at the Diagnostic Centre I have to do what I am trained for - I have to take on the role of a physician. If I don't, we won't succeed in our efforts to diagnoses the patient quickly.

The necessity for the physician to go "back to the core", produces another professional outcome: that of broader and more in-depth medical knowledge and expertise. This outcome is created by the perceived necessity to acquire new, as well as refresh old, knowledge in order to possess the right "tools" to enable timely diagnosis, as the patients might be suffering from any manner of afflictions. The physicians acquire professional knowledge through studying both old and new medical texts, driven by the aforementioned requirement to be up to date, but also by the need to possess the appropriate terminology when communicating with the range of medical specialists with whom the physician comes into contact throughout the diagnostic process. As previously mentioned, the responsible physicians at the DC often refer to specific medical expertise in order to make their judgements in relation to potential diagnosis. For such a referral to be performed smoothly, the responsible physician must have a fairly comprehensive understanding of the relevant expertise to know what medical
Healthcare through value shops 
IJHG

25,2

investigations to ask for as well as to interpret the results in order to evaluate the impact it might have on the on-going diagnosis of the patient. To sum up, the professional fulfilment of the respective physician at the $\mathrm{DC}$ is facilitated through the demand to make a fast diagnosis, while enabled and pre-conditioned by the rare opportunity to work intensively with a specific patient, and not bound by strict limitations on resources in the exercise of professional discretion.

\section{Professional fulfilment for nurses}

Similarly to the physicians, the nurses at the respective DC state that they were able to go "back to the core" of their profession. The nurses' initial contact with the patient was often within one to two days after they had been admitted to the DC. The aim was to book the patient's first visit as soon as possible. Instead of relying on postal communication, which is common in the Swedish health service, the nurses called the patient. As a result, the patient's first visit to the DC usually took place quickly - even as early as the day after first contact with the nurse. Although it is common for more than one nurse to be allocated to the DC, the staff members wanted the same nurse who had first contact with the patient to also handle further communication and contact with the patient. Consequently, each nurse managed their "own" patients throughout the processes at the DC. This enabled them to truly care for them in a way that they feel they rarely had the opportunity to do elsewhere. One of the nurses illustrates this notion by stating that:

I find it satisfying to give the patient comfort. My work here is so much more about caring, comforting and palliating than is customary. Despite the fact that the patients at the Diagnostic Centre are often very ill, with poor predicted outcomes, they are grateful and pleased with the care we are able to provide. I feel that our work here really makes a difference for them.

The nurses felt that this approach was facilitated by the fact that they were able to "follow" the patients; from the moment that first contact was made until the diagnosis or lack of diagnosis. As this process is intended to take no more than 18 days, the intense contact that takes places between the patient and (often the same) nurse enables a more than usually intimate bond to be formed between them. Moreover, the patients were able to call their nurse whenever they felt the need. As the patient always knew which nurse was going to answer, it enabled a bond to be established between the nurse and them. "We know who they are and we know everything about them" as one of the nurses describes this unique bond. To sum up, the DC allows nurses to get back to what they perceive to be their "professional core" in that they are able to provide extensive and intensive care, and cater for the patients' needs.

\section{Concluding discussion}

The involvement and engagement of healthcare professionals is a cornerstone in ensuring the success of QI in healthcare settings (Batalden and Davidoff, 2007; Gadolin and Andersson, 2017). Despite this, there is a lack of studies focussing on how physicians and nurses are able to attain professional fulfilment when engaged in providing care inspired by the "value shop". This paper has shown that the physicians and nurses involved in the DC - a way of organizing care inspired by the "value shop" - perceived that they are able to go back to their "professional core". The descriptions provided by the physicians and nurses in relation to their work at the DC may therefore be understood as facilitating their attainment of professional fulfilment. For the physicians, this means that they are able to work intensively with patients in order to achieve timely diagnoses, with no managerial interference in relation to resource utilization. This way of working enabled the physicians to utilize their unique medical expertise extensively and do things they felt other professions could not. For the nurses, going back to their "professional core" entailed them being able to care for the patient 
in ways they felt were unique. Both these ways of working related to what has previously been defined as “core" in relation to both profession's professional work (Freidson, 2001; Glouberman; Mintzberg, 2001; Andersson, 2015; Gadolin, 2017).

Professional fulfilment is vital in ensuring the involvement and engagement of healthcare professionals in QI work while facilitating their mental health and high-quality care (Båăthe and Norbäck, 2013; Lindgren et al., 2013; Andersson, 2015; Gadolin and Andersson, 2017; Trockel et al., 2018). This paper consequently addresses the discourse regarding the importance of organization and management practice in healthcare (Ramanujam and Rousseau, 2006) in suggesting that the ability to facilitate healthcare professionals' professional fulfilment when organizing care inspired by the "value shop" is another factor that needs to be taken into consideration when evaluating the potential outcomes and benefits of such organizing. In addition to having the potential to mitigate patients' experience of care as fragmented, reduce its cost and achieve higher-quality (Gui et al., 1995; Tang and Lee, 2009; Moore et al., 2009; Bredenhoff et al., 2010; Cook et al., 2014; King, 2016; Friedemann Smith et al., 2019; van Leersum et al., 2019), organizing care inspired by the "value shop" may have a profound impact upon how healthcare professionals experience their own role and function in the provision of care. Whereas the Swedish healthcare system is to some extent idiosyncratic, the degree of public funding being one of its characteristics (OECD, 2015), the challenges associated with a more fragmented healthcare system as a result of recent reforms is an international phenomenon (Eriksson et al., 2020). The findings of this paper are thus relevant for both policy makers and managers globally who are trying to mitigate the effects of more complex and fragmented healthcare systems with the intention of achieving integrated care for patients who tend to see multiple care providers. In addition, the findings further strengthen the necessity of aligning QIs in healthcare settings with the professional logics of healthcare professionals (e.g. Reay et al., 2017: Anderson and Liff, 2018; Ernst, 2019). Future research needs to be put into relevant related aspects and should explore the potentially changed roles of professions in the "value shop" as compared to the "value chain" in order to further advance our understanding of its organizational consequences. Moreover, the way healthcare professionals interact and build relationships when working within a "value shop" should also be further investigated, as constructive working relationships are vital in obtaining QIs in healthcare (cf. Gadolin and Anderson, 2017).

\section{References}

Alvesson, M. and Sköldberg, K. (2009), Reflexive Methodology: New Vistas for Qualitative Research, SAGE Publications, London.

Andersson, T. (2015), "The medical leadership challenge in healthcare is an identity challenge", Leadership in Health Services, Vol. 28 No. 2, pp. 83-99.

Andersson, T. and Liff, R. (2018), "Co-optation as a response to competing institutional logics: professionals and managers in healthcare", Journal of Professions and Organization, Vol. 5 No. 2, pp. 71-87.

Audet, A.M.J., Doty, M.M., Shamasdin, J. and Schoenbaum, S.C. (2005), "Measure, learn, and improve: physicians' involvement in quality improvement", Health Affairs, Vol. 24 No. 3, pp. 843-853.

Bååthe, F. and Norbäck, L.-E. (2013), "Engaging physicians in organisational improvement work", Journal of Health Organization and Management, Vol. 27 No. 4, pp. 479-497.

Barritt, P. (2005), Humanity in Healthcare: The Heart and Soul of Medicine, Radcliff Publishing, Oxford.

Batalden, P. and Davidoff, F. (2007), "What is 'quality improvement' and how can it transform healthcare?”, BMJ Quality and Safety, Vol. 16 No. 1, pp. 2-3. 
IJHG

25,2
Bevan, H. (2010), "How can we build skills to transform the healthcare system?", Journal of Research in Nursing, Vol. 15 No. 2, pp. 139-148.

Bredenhoff, E., van Lent, W.A. and van Harten, W.H. (2010), "Exploring types of focused factories in hospital care: a multiple case study", BMC Health Services Research, Vol. 10 No. 1, p. 154.

Carroll, J.K., Humiston, S.G., Meldrum, S.C., Salamone, C.M., Jean-Pierre, P., Epstein, R.M. and Fiscella, K. (2010), "Patients' experiences with navigation for cancer care", Patient Education and Counseling, Vol. 80 No. 2, pp. 241-247.

Cebul, R.D., Rebitzer, J.B., Taylor, L.J. and Votruba, M.E. (2008), "Organizational fragmentation and care quality in the US healthcare system", Journal of Economic Perspectives, Vol. 22 No. 4, pp. 93-113.

Chassin, M.R. and Galvin, R.W. (1998), "The urgent need to improve health care quality", JAMA, Vol. 280 No. 11, pp. 1000-1005.

Chassin, M.R., Loeb, J.M., Schmaltz, S.P. and Wachter, R.M. (2010), "Accountability measures - using measurement to promote quality improvement", New England Journal of Medicine, Vol. 363 No. 7, pp. 683-688.

Chen, W., Zheng, R., Baade, P.D., Zhang, S., Zeng, H., Bray, F., Jemal, A., Qin, Y.X. and He, J. (2016), "Cancer statistics in China, 2015", CA: A Cancer Journal for Clinicians, Vol. 66 No. 2, pp. 115-132.

Christensen, C., Grossman, J. and Hwang, J. (2009), The Innovator's Prescription: A Disruptive Solution for Health Care, McGraw-Hill, New York.

Christensen, T. and Lægreid, P. (2011), "Democracy and administrative policy: contrasting elements of new public management (NPM) and post-NPM", European Political Science Review, Vol. 3 No. 1, pp. 125-146.

Cook, D., Thompson, J.E., Habermann, E.B., Visscher, S.L., Dearani, J.A., Roger, V.L. and Borah, B.J. (2014), "From 'solution shop' model to 'focused factory' in hospital surgery: increasing care value and predictability", Health Affairs, Vol. 33 No. 5, pp. 746-755.

Corwin, R.G. (1961), "The professional employee: a study of conflict in nursing roles", American Journal of Sociology, Vol. 66 No. 6, pp. 604-615.

Ernst, J. (2019), "The curse of bureaucratization or the blessings of professionalisation? Nurses' engaged adoption of quality management in hybrid managerial positions", Scandinavian Journal of Management, Vol. 35 No. 3, 101050, doi: 10.1016/j.scaman.2019.101050.

Eriksson, E. (2016), "A service management perspective on healthcare improvement”, Doctoral Dissertation, Chalmers University of Technology, Gothenburg.

Eriksson, E., Hellström, A., Andersson, T., Gadolin, C. and Lifvergren, S. (2020), "Collaborative Public Management: coordinated calue propositions among public service organisations", Public Management Review, Forthcoming, doi: 10.1080/14719037.2019.1604793.

Frandsen, B.R., Joynt, K.E., Rebitzer, J.B. and Jha, A.K. (2015), "Care fragmentation, quality, and costs among chronically ill patients", The American Journal of Managed Care, Vol. 21 No. 5, pp. 355-362.

Friedemann Smith, C., Tompson, A., Holtman, G.A., Bankhead, C., Gleeson, F., Lasserson, D. and Nicholson, B.D. (2019), "General practitioner referrals to one-stop clinics for symptoms that could be indicative of cancer: a systematic review of use and clinical outcomes", Family Practice, Vol. 36 No. 3, pp. 255-261.

Freidson, E. (1986), Professional Powers, University of Chicago Press, Chicago.

Freidson, E. (2001), Professionalism: The Third Logic, University of Chicago Press, Chicago.

Gadolin, C. (2017), "The logics of healthcare - in quality improvement work", Doctoral Dissertation, University of Gothenburg, Gothenburg.

Gadolin, C. (2018), "Professional employees' strategic employment of the managerial logic in healthcare", Qualitative Research in Organizations and Management, Vol. 13 No. 2, pp. 126-143. 
Gadolin, C. and Andersson, T. (2017), "Healthcare quality improvement work: a professional employee perspective", International Journal of Health Care Quality Assurance, Vol. 30 No. 5, pp. 410-423.

Glouberman, S. and Mintzberg, H. (2001), "Managing the care of health and the cure of disease - part I: differentiation”, Health Care Management Review, Vol. 26 No. 1, pp. 56-69.

Gui, G.P., Allum, W.H., Perry, N.M., Wells, C.A., Curling, O.M., McLean, A., Oommen, R. and Carpenter, R. (1995), "One-stop diagnosis for symptomatic breast disease", Annals of the Royal College of Surgeons of England, Vol. 77 No. 1, pp. 24-27.

Hsieh, H.F. and Shannon, S.E. (2005), "Three approaches to qualitative content analysis", Qualitative Health Research, Vol. 15 No. 9, pp. 1277-1288.

Hwang, J. and Christensen, C.M. (2008), "Disruptive innovation in health care delivery: a framework for business-model innovation", Health Affairs, Vol. 27 No. 5, pp. 1329-1335.

Kern, L.M., Seirup, J.K., Rajan, M., Jawahar, R., Miranda, Y. and Stuard, S.S. (2019), "Extent of health care fragmentation in different payer populations: evidence from the Hudson valley of New York", Population Health Management, Vol. 22 No. 2, pp. 138-143.

King, K.E. (2016), "Patient satisfaction in a one-stop haematuria clinic and urology outpatients: a comparison of clinics", International Journal of Urological Nursing, Vol. 10 No. 3, pp. 127-136.

Lindgren, A., Bååthe, F. and Dellve, L. (2013), "Why risk professional fulfilment: a grounded theory of physician engagement in healthcare development", The International Journal of Health Planning and Management, Vol. 28 No. 2, pp. e138-e157.

Miles, M.B. and Huberman, A.M. (1994), Qualitative Data Analysis: An Expanded Sourcebook, SAGE, Thousand Oaks.

Moore, J.A., O’Neil, C. and Fawcett, D. (2009), “A one-stop clinic for men with testicular anxiety”, The Annals of The Royal College of Surgeons of England, Vol. 91 No. 1, pp. 23-24.

Nolte, E., Knai, C., Hofmarcher, M., Conklin, A., Erler, A., Elissen, A., Flamm, M., Fullerton, B., Sönnichsen, A. and Vrijhoef, H.J. (2012), "Overcoming fragmentation in health care: chronic care in Austria, Germany and The Netherlands", Health Economics, Policy and Law, Vol. 7 No. 1, pp. 125-146.

OECD (2015), Health at a Glance 2015: OECD Indicators, OECD Publishing, Paris.

Osborne, S.P., Radnor, Z., Kinder, T. and Vidal, I. (2015), "The SERVICE framework: a public-servicedominant approach to sustainable public services", British Journal of Management, Vol. 26 No. 3, pp. 424-438.

Otte-Trojel, T., de Bont, A., Aspria, M., Adams, S., Rundall, T.G., van de Klundert, J. and de Mul, M. (2015), "Developing patient portals in a fragmented healthcare system", International Journal of Medical Informatics, Vol. 84 No. 10, pp. 835-846.

Ouwens, M., Wollersheim, H., Hermens, R., Hulscher, M. and Grol, R. (2005), "Integrated care programmes for chronically ill patients: a review of systematic reviews", International Journal for Quality in Health Care, Vol. 17 No. 2, pp. 141-146.

Pollitt, C. (2003), “Joined-up government: a survey”, Political Studies Review, Vol. 1 No. 1, pp. 34-49.

Porter, M. (1985), Competitive Advantage, Free Press, New York, NY.

Ramanujam, R. and Rousseau, D. (2006), "The challenges are organizational not just clinical”, Journal of Organizational Behavior, Vol. 27 No. 7, pp. 811-827.

Reay, T. and Hinings, C. (2009), "Managing the rivalry of competing institutional logics", Organization Studies, Vol. 30 No. 6, pp. 629-652.

Reay, T., Goodrick, E., Waldorff, S.B. and Casebeer, A. (2017), "Getting leopards to change their spots: co-creating a new professional role identity", Academy of Management Journal, Vol. 60 No. 3, pp. 1043- 1070.

Silverman, D. (2001), Interpreting Qualitative Data, SAGE Publications, London.

Stabell, C. and Fjeldstad, Ø. (1998), "Configuring value for competitive advantage: on chains, shops, and networks", Strategic Management Journal, Vol. 19, pp. 413-437. 
IJHG

25,2

Tang, V. and Lee, E. (2009), "Simplified one-stop clinic", British Journal of Healthcare Management, Vol. 15 No. 12, pp. 592-596.

Thomsen, S., Soares, J., Nolan, P., Dallender, J. and Arnetz, B. (1999), "Feelings of professional fulfilment and exhaustion in mental health personnel: the importance of organisational and individual factors", Psychotherapy and Psychosomatics, Vol. 68 No. 3, pp. 157-164.

Trockel, M., Bohman, B., Lesure, E., Hamidi, M.S., Welle, D., Roberts, L. and Shanafelt, T. (2018), "A brief instrument to assess both burnout and professional fulfillment in physicians: reliability and validity, including correlation with self-reported medical errors, in a sample of resident and practicing physicians", Academic Psychiatry, Vol. 42 No. 1, pp. 11-24.

Utriainen, K. and Kyngäs, H. (2009), "Hospital nurses' job satisfaction: a literature review", Journal of Nursing Management, Vol. 17 No. 8, pp. 1002-1010.

Van den Broek, J., Boselie, P. and Paauwe, J. (2014), "Multiple institutional logics in health care: 'productive ward: releasing time to care", Public Management Review, Vol. 16 No. 1, pp. 1-20.

van Leersum, N., Bennemeer, P., Otten, M., Visser, S., Klink, A. and Kremer, J.A. (2019), "Cure for increasing health care costs: the Bernhoven case as driver of new standards of appropriate care”, Health Policy, Vol. 123 No. 3, pp. 306-311.

\section{Corresponding author}

Christian Gadolin can be contacted at: christian.gadolin@hv.se

For instructions on how to order reprints of this article, please visit our website:

www.emeraldgrouppublishing.com/licensing/reprints.htm

Or contact us for further details: permissions@emeraldinsight.com 